Article

\title{
Sustainable Initiatives in Sports Organizations-Analysis of a Group of Stakeholders in Pandemic Times
}

\author{
Ricardo Roseira Cayolla ${ }^{1}\left(\mathbb{D}\right.$, Teresa Santos $^{2}$ and Joana A. Quintela ${ }^{3, *}$ \\ 1 Department of Economics and Management, Universidade Portucalense, 4200-072 Porto, Portugal; \\ rcayolla@upt.pt \\ 2 Quality and Environmental Manager at Futebol Clube do Porto, 4350-414 Porto, Portugal; \\ teresa.santos@fcporto.pt \\ 3 Department of Tourism, Heritage and Culture, Universidade Portucalense, 4200-072 Porto, Portugal \\ * Correspondence: jquintela@upt.pt
}

check for updates

Citation: Cayolla, R.R.; Santos, T.; Quintela, J.A. Sustainable Initiatives in Sports Organizations-Analysis of a Group of Stakeholders in Pandemic Times. Sustainability 2021, 13, 9122. https://doi.org/10.3390/su13169122

Academic Editor: José Carmelo Adsuar Sala

Received: 6 July 2021

Accepted: 9 August 2021

Published: 14 August 2021

Publisher's Note: MDPI stays neutral with regard to jurisdictional claims in published maps and institutional affiliations.

Copyright: (c) 2021 by the authors. Licensee MDPI, Basel, Switzerland. This article is an open access article distributed under the terms and conditions of the Creative Commons Attribution (CC BY) license (https:// creativecommons.org/licenses/by/ $4.0 /)$.

\begin{abstract}
This study explores the importance of environmentally sustainable initiatives in sport (ESIS) for stakeholders in pandemic times. Three topics-climate changes and energy consumption, environmental impact of sports events, and health and well-being-were considered and analysed under three sustainability forms: organisational, community, and individual. A total of 5917 stakeholders (sponsors, employees, and members) of a sports organization realised one online survey. The data gathering process occurred during pandemic times, when every kind of collective sport event was suspended to the general public. The descriptive analysis of the results is provided, and the findings reveal that health and well-being is the most valorised topic by members and employees, in a sustainable individual form. On the other hand, sponsors manifest their interest mainly in a sustainability organisational and community forms.
\end{abstract}

Keywords: environmentally sustainable initiatives in sports (ESIS); sports organizations (SO); health and well-being; stakeholders

\section{Introduction}

Several organizations have tried to measure and monitor proximity, through metrics and sustainability indicators, in the perspective of Sustainable Development, considering it is "progress that meets the needs of the present without compromising the ability of future generations to satisfy their own needs", as defined on the Brundtland Report [1] (p. 24). Within these organizations are sports organizations. Sports industry, in particular professional sports organizations, has an enormous capacity to influence consumer behaviour [2-4]. There are various stakeholders that make up the "modus vivendi" of these organizations (e.g., members, employees, sponsors). In a transversal way, economic, social, and environmental sustainability starts to be a dominant theme in society. Outlining sport in a comprehensive way, including all parties involved (players, managers, fans, among others), sport ecology studies the relationship between sport and the natural environment in a reciprocal manner [5].

Professional sports organizations, concerning environmental sustainability, have gradually come to carry out initiatives with the aim of sensitizing their stakeholders, thus expecting direct and indirect gains. However, there is a huge lack of knowledge of these initiatives regarding the results [6], and further analysis and strategies should be followed [7]. Some important questions come up when sustainable initiatives are executed. Which and how many stakeholders are aware of the initiatives carried out? How important is individual health and well-being in the sustainable initiatives? What is the perception of stakeholders regarding the performance of the sports organization in these types of initiatives? Among the various stakeholders, are there differences in the sustainability forms 
between stakeholders, according to their behaviors? With regard to environmental sustainability initiatives, these and many other questions remain unanswered, or the answers given are inconclusive. By carrying out quantitative studies in a group of stakeholders of a professional sports organization, the objective of this investigation is to contribute to the development of sport ecology through a case study of football, "the world's most popular sport" [8] (p. 281).

The visibility that sport has allows reaching an audience of millions of people, from all social classes, relating the possibility of doing business in the most varied sectors [9]. Professional sports organizations are extremely powerful in the world [10], being able to influence the environmental behavior of the various stakeholders [2-4]. In fact, due to its past of community involvement, civic engagement, and social well-being, the more frequent carrying out of sustainability initiatives by professional sports organizations "can be seen as an extension of their social responsibility" [11] (p. 76).

Every day, millions of users take advantage of the services provided by sports organizations [7]. The characteristics of the sports industry, with the high number of fans traveling to the games, the various consumptions made during the events (i.e., energy, food), the construction of large infrastructures with the consequent necessary maintenance, the trips of the teams and all the associated logistics, among others, make this industry highly impacting on the environment [12].

At the level of sports organizations, sustainability appears as a strategy that aims to improve economic and social objectives [13]. The implementation of sustainability initiatives allows not only a boost in the experience lived by the fans, but also a closer relationship with the community [11]. Spectators, due to the relationship with their favorite team, through their behavior are the main contributors of $\mathrm{CO}_{2}$ emissions [14,15]. The study of sport ecology, although it has a special focus on North America and Europe [9], has been consolidated in all parts of the globe, as shown by studies in the Asia-Pacific region $[16,17]$ and South America $[18,19]$.

Increasingly, the general public is interested in climate change. Regardless of the industry, consumers tend to value sustainable products and brands [5]. As a result, organizations frequently publish sustainability reports that support their sustainability-related efforts. The authors conclude that, curiously, in the sports sector, this does not happen. The same goes for teaching environmental sports sustainability, with academic organizations being slow in designing and implementing pro-environmental strategies [17,20-23]. Extending previous investigations [24,25], Wall-Tweedie and Nguyen (2018) claim that "the academic literature pertaining to Environmental Sustainability (ES) and sport has been reported to be in its infancy" [17] (p. 743).

Considering this fact, it seemed particularly important to develop a research work that would allow understanding of what extent sports organizations are considered legitimate to convey environmental messages, related to the promotion of environmental behaviors. This approach was developed from a supply and demand perspective, considering sponsors, employees and members (SEM), and analyzes the impact of environmentally sustainable initiatives in sports (ESIS) on a triple level (organizational, community and individual), based on Lindsey (2008) [26].

Developed on prior literature and the narrow understanding of stakeholder's results concerning environmentally sustainable initiatives in sport (ESIS) promoted by sport organizations, the present study aimed to contribute to the nascent field of sport ecology by analysing, through quantitative methods, the awareness of relevant topics of stakeholders of a professional football club and its positioning as a sustainability form. Accordingly, two quantitative studies with a group of stakeholders support this article concerning ESIS:

- Study 1: identifies who is aware of the ESIS, which is the most important topic, and it investigates the categorization regarding the organization's performance concerning ESIS.

- $\quad$ Study 2: analyses the differences between the different groups of stakeholders in the topics covered. 
This paper follows an organized sequence based firstly in a more detailed literature relating to the three forms of sustainability that emerged from the analysis, in order to define the purpose and the research goals. Research hypotheses are enlightened and a conceptual research model is designed. The methodology section focused on the description of the empirical study, mentioning the data gathering process and data treatment. Results for study 1 and study 2 are then presented and discussed in relation to the literature. Theoretical contribution and managerial implications are highlighted. General conclusions are drawn, research limitations are mentioned, and recommendations are expressed, regarding the extension of knowledge on sports sustainability development.

\section{Theoretical Background}

Sport can be an instrument for constructive societal transformation. As a significant symbol of popular culture, professional football, "has the potential to transform how we view and practice sustainability" [27] (p. 396). Sports organizations increasingly engage in environmentally friendly business practices. For McCullough and Cunningham (2010) [28], there are several pressures (functional, political, social) that can positively influence the adoption of environmental sustainability practices by sports organizations. The authors conclude that in addition to immediate advantages (cost reduction, increased competitive advantage, perceptions of goodwill on the part of consumers), such initiatives can increase fan identification, one of the main objectives of the sports industry. Extending past research [7,12,28-32], it is our goal to acknowledge how stakeholders (i.e., members, employees, and sponsors) feel the perceived effects regarding relevant topics of action for a sport organization in the scope of environmental sustainability.

In research of the concept of sustainability in sports development, Lindsey (2008) [26] found a similarity between different authors and their respective proposals. After identifying a lack of clarity and little theory, it presents an applicable proposal to sustainability in sports development based on concepts of health literature. This is established on a model that identifies four forms of sustainability, hierarchically equal, without levels: individual, community, organisational, and institutional. Following the same line of reasoning [26] the concepts will be adjusted and adapted to a format that allows analysis of the results of different stakeholders in the panorama of environmental sustainability of a sports organization. In this way, taking into account that Lindsey (2008) [26] defines institutional sustainability as requiring more time and a broader context, it will not be used. The forms of individual, community, and organisational environmental sustainability will be used, properly framed with the topics analysed. In the questionnaire carried out, several topics were addressed. For this study, concerning environmental sustainability, the topics considered were: (a) climate changes and energy consumption (CC); (b) environmental impact of sporting events (EI); (c) promotion of health and well-being (HW) (see Figure 1).

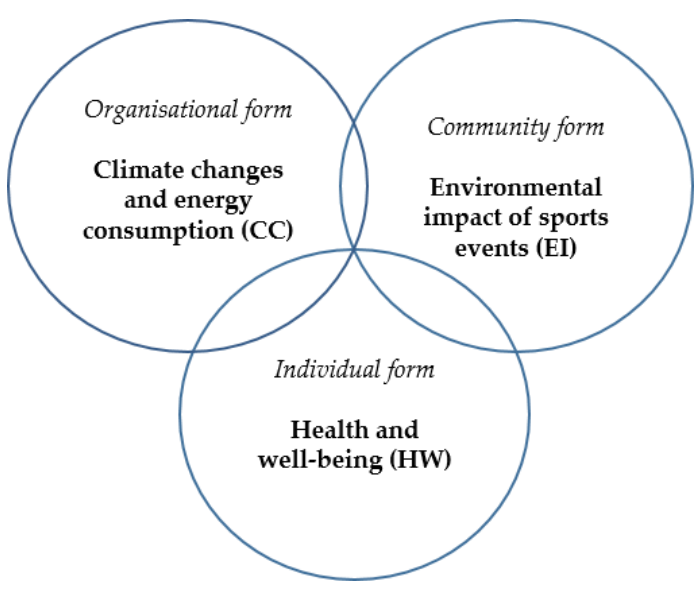

Figure 1. Sustainability forms in sports organizations' initiatives, adapted from Lindsey (2008) [26]. 


\subsection{Climate Change and Energy Consumption}

Knowing that the links between the sports economy and the environment have already been studied [33], in football, like other sports (e.g., basketball or American football), factors such as team quality, market potential and exhibition quality are key in capturing audiences, as well as in later understanding of consumer behaviour [34]. Consumers are increasingly demanding about the service provided by sports organizations. The construction of large sports stadiums is part of the development process of the sports industry, but has an associated environmental cost [14]. Curiously, one of the goals of building these infrastructures is to reduce $\mathrm{CO}_{2}$ emissions, which is paradoxical [29].

With regard to the environmental conditions in which professional competitions take place, a study about spectators of the Chinese Super League (CSL) leaves no doubt; consumer habits are not affected by the presence of air pollution [35]. At the time of the study, the body that oversees CSL did not encourage the creation of environmental rules with the aim of promoting consumer health or CSL's global policy. However, in the authors' conclusions, for the better functioning of the CSL and to attract new audiences, it is crucial to establish environmentally friendly measures. Whether on a more specific and short-term plan, or more global and long-term, climate change requires modifications that are felt in the most diverse scenarios. For example, when traveling to stadiums, fans use public transport as their main means of transport or, as an alternative, share their car with other fans. In the facilities where the events take place, having different containers for garbage is another situation that is increasingly recurrent in sports organizations concerned with the environment. This requires a waste treatment and transport system that goes beyond the mere receptacle to receive garbage. The organizing entities or their partners (i.e., sponsors) plan awareness-raising actions that reward (e.g., with event tickets) environmentally friendly behavior or reward members with discounts on the purchase of material or associated services. These are just a few ideas that leverage greater stakeholder awareness of environmental issues.

Although it is a little noticed reality, there are already sports that are obliged to anticipate the way in which their practice has to be carried out (e.g., cross-country skiing) [36]. At the global level, and with long-term strategic thinking, the number of cities available to host major multisport events (e.g., Olympic Games) tends to decrease. In order to reverse this reality, we need a multidisciplinary collaboration with special emphasis on facilities management, communication, sports marketing, and sports psychology [32].

Although slowly, environmental sustainability (ES) has been gaining ground and credibility, requiring greater investment and visibility toward the initiatives carried out [37]. The fact that professional sports organizations are paying more and more attention to climate change and the energy consumption of their facilities has nothing to do with charity. Such results can be gauged on a more concrete (i.e., fan) or a more abstract level (i.e., credibility in society). Remarkable work $[2,15,30]$ revealed that a sports organization can have a huge influence, through sustainability campaigns, in influencing the behavior of sports fans, both in the events themselves and in their daily lives. In addition, these works determined that fans least identified with the team strengthen their ties with the team due to the organization's commitment to environmental sustainability. On the other hand, Babiak and Trendafilova (2011) [28], through the use of institutional theory, concluded that the sustainability practices used by sports organizations allow a double advantage; first, credibility with stakeholders; second, protecting the organization from possible criticism. In this way, the authors add, towards the general public, the positive effect of the way of doing business on the part of the organization increases. Since there are already standard procedures, as well as environmental protection policies, much remains to be done in terms of monitoring and reporting $[23,38]$.

\subsection{Environmental Impact of Sporting Events}

With regard to major sporting events held on a seasonal basis (e.g., every four years), such as the Federation International Football Association (FIFA), the World Cup, or the 
Olympic Games, studies show that around three million spectators travel an average of $4000 \mathrm{~km}$ to be able to be present at these major events [39]. It is an indisputable fact that in recent years there has been an exponentially increasing number of spectators who travel to see a sports show [40], whether this is frequent or seasonal. This trend is also seen in the increase in the number of spectators who follow their favorite teams, in addition to home games [38].

Considering sport ecology research, Thibault (2009) [41] has developed several studies to understand not only the production of different forms of pollution, but also the environmental effect that sporting events produce. One of the characteristics of sports is related to its enormous variety and organizational and performance complexity, which can be studied from the point of view of the spectator itself or of the practitioner. The environmental impact related to the attitude of the spectators has been the subject of several studies, in the field of football, rugby, or the Tour de France [42]. In baseball, a mass sport in the United States, a research was made concerning the influence that the spectator has on the local air pollution, and was considered irrelevant [43]. At the university level, the effects of transportation that football spectators produce on air quality were also studied [44]. As for the study of the carbon footprint of sport participants, there is the paradox that individuals with a greater environmental awareness (i.e., participants in sports in nature) are not the ones who most protect the environment due to the essence of their own activity [45].

Strategies to reduce environmental impact have also been the focus of attention by researchers. The holding of major sporting events has associated costs with regard to the environment. Regardless of the pressure exerted by environmental activists [46], the results of environmental sustainability initiatives often fall short of expectations. In a top-down logic, the promise of a positive inheritance in what concerns the environment is faced with several difficulties in its execution (e.g., due to the complexity of the project itself, or the measurability of the environmental impact itself) [47]. In a bottom-up approach, although there are examples of organizations that show proactivity in the construction of environmentally friendly stadiums [48], there are several factors that contribute to a slow diffusion in the adoption of a sustainable design of new installations by the decision makers, such as narrow financing or inadequate manpower [49]. In addition to the aforementioned, the very implementation of pro-environmental initiatives is struggling with the difficulty of collecting information and subsequent appropriate planning [50]. As far as fans are concerned, from a perspective of attracting new fans [51] or permanence of current fans [15] in terms of environmental sustainability, a lot has been done by the academy in order to understand what are the best methods to seduce fans [52].

\subsection{Promotion of Health and Well-Being}

Sport can be seen as an instrument that generates dynamics that integrate wills, enhance changes, and create great impacts on the cultural, social, and environmental environment. In this way, sport, represented by the respective organizations and companies, public or private, can be considered an important agent in terms of sustainability, acting according to the principles inherent to the concept, and promoting a set of initiatives in this area, including the health and well-being dimension [53]. Throughout human history, the pursuit of health has been among the primary aims of individuals, communities, national governments, and international initiatives [54].

The social and political context of the 1980s, such as the rise of economic globalization, influenced health policy directions as much as other aspects of modern life [55], underlining the importance of health for the contemporary societies. "The Ottawa Charter" of 1986 marked the innovative approach of public health from traditional epidemiological and surveillance methods towards a more environmental and social model [56]. This new ecological approach emphasizes the interconnections between humans and their physical and social environments and their health.

The concepts of health and well-being converge and diverge, both theoretically and in practice [57]. Throughout time, there have been changing philosophies and attitudes 
to health [55]. The concept of health has been enlarged by WHO (1948) [58], stating that "health is a state of complete physical, social and mental well-being, and not merely the absence of disease or infirmity" (p. 1). This enlarged definition of the concept expresses the contemporary perspective of health, defined in the mid-twentieth century, when the human population struggled less with communicable diseases and more with lifestylerelated conditions.

In the last decades, the search for health has been increasingly considered as a synonym for well-being, happiness, and long life [59]. Currently, health is part of a social framework where there is a growing awareness of the body and mind. The so-called "diseases of civilization" abound, which lead many people to seek new ways of being and feeling, both on a physical and psychological level, privileging the paradigm of health and well-being recommended by WHO (World Health Organization), where sports occupy an important role [58]. The connection between health, well-being and sports has been recently reported by the literature in the field of health, although it remains necessary to systematize the approach between the two concepts $[60,61]$.

The importance of health in sports organizations is fully in harmony with the sustainable development agenda, clearly expressed in the Sustainable Development Goals (SDG) stated by "Goal 3: Ensure healthy lives and promote well-being for all at all ages" [62] (p. 18). Considering this statement, sport organizations should consider enlarging their strategic and operational goals, focused on their potential to contribute to the well-being of individuals and communities [63]; ESIS fit in this scenario.

However, the emergence of COVID-19 came to reinforce this statement. The pandemic provoked a health crisis and a global financial decline, due also to the lockdown policies that restricted the individual and collective mobility, forcing important changes to lifestyle [64]. These general restrictions imposed by the COVID-19 pandemic provoked significant social changes and affected several sectors at the global scale, including the sport industry by having an impact and altering the normal development of sport competitions and events [65]. Due to social distance being one of the most important rules to control the virus proliferation, leisure activities, namely the participation on sports manifestations, were suspended, significantly influencing the psychological state of individuals [66] at an individual and social level.

Considering sport contributes to well-being, that fact also affected the psychological health of sports organizations stakeholders [67]. The new situation also represented a challenge in terms of managing the multiplicity of companies linked to the sports sector, forcing them to define new business models compatible with the changes imposed, namely in terms of entrepreneurship [68]. This climate of change may also represent the emergence of new opportunities, where the health and sustainability factors will be inseparable in the future.

\section{Questioning and Confirming Hypotheses}

With regard to sustainability, a lacuna remains among the sport industry efforts and academic work $[7,26]$. As for the way sports organizations evaluate the sustainability campaigns they carry out, these are non-existent or incipient [6]. Taking into account the reality, it is very clear that there is a need for more academic work in order to be able to more accurately transmit the efforts made by the sports industry with regard to environmental sustainability [7]. Following the work of McCullough, Pelcher and Trendafilova (2020) [32], we want to assess the extent to which sports organizations are perceived as legitimate to convey environmental messages related to the promotion of environmental behaviors. Finally, this work also aims to continue to explore and evaluate the effectiveness of marketing in the area of environmental sustainability [7]. Academic research can contribute to the broadening of knowledge in this area from both a supply and demand perspective, monitoring initiatives carried out by different types of sports organizations. In addition to the analysis of their impact at different levels, other studies should assess the degree of involvement and satisfaction of participants through sustainable 
initiatives, as well as analyze their contribution to the definition of management strategies. It will be also possible to evaluate the evolution of these initiatives in the medium and long term by longitudinal studies.

Thus, for study 1, the following questions are considered: Assuming that sports organizations are credible in communicating the promotion of environmentally sustainable behaviors to the various stakeholders (e.g., members, employees, and sponsors): (1) what is the percentage of awareness of those initiatives? (2) globally, how important is the health topic? (3) through ESIS, how is the sports organization ranked by the stakeholders?

We adapted the Lindsey (2008) [26] model not only to try to understand better sustainability in sports, but also to assess "the degree to which particular forms of sustainability are achieved" (p. 292). Even knowing that the effort of environmental sustainability, on the part of the sport industry, is a reality, it becomes necessary to thoroughly assess the reactions of interested parties (e.g., members, employees, and sponsors) to the efforts made in favor of environmental sustainability [32]. In management, partnerships are not as worked on as strategy and decision making; however, sponsors are vitally important to the survival and competitiveness of sports organizations. For Trendafilova and McCullough (2018) [7], in terms of international partnerships and collaborations, more needs to be done. We seek to extend past work [30] by trying to understand the extent to which sport is seen by sponsors as a platform that enhances sustainability efforts, thereby leveraging the brand. Additionally, in the wake of the work of Trendafilova and Babiak (2013) [12], knowing the opinions of sports sponsors about the meaning they give to environmental initiatives in the sports entities with which they work is paramount, benefiting both entities (i.e., the sponsors and partner organizations). Consequently, for study 2 , the following question is formulated: As for the topics analysed, what is the position of each stakeholder as a form of sustainability?

This work also aims to continue to explore and evaluate the effect that ESIS have on the behavior of the various stakeholders, extending past research $[3,4,7]$.

\section{Research Hypotheses and Conceptual Research Design}

Study 1

Study 1 is composed of three main research hypotheses, multiplied according to the different groups of stakeholders: sponsors $(\mathrm{Ha})$, employees $(\mathrm{Hb})$ and members $(\mathrm{Hc})$. The first hypothesis (H1) is supported by the empirical data and it captures the level of awareness of the different groups of sports organization stakeholders on environmental initiatives. In the sense that sporting events are increasingly spectacles characterized by the need to capture audiences, Climate change and energy consumption arises as a paradoxical topic; to satisfy an increasingly demanding consumer, organizations need to spend more energy, with repercussions on the environment around us [14,29,33,34]. About the topic Environmental impact of sporting events, the execution and reporting of sustainability actions becomes difficult due to the enormous complexity involved [47-49]. Lastly, regarding Promotion of Health and Well-being, it is understood from a holistic perspective as a quality of life, properly framed in the pandemic situation we are experiencing [59,63-67].

Due to lack of measures [6] or the lack of publicity about them [5], it is our intention to know and disseminate the level of knowledge that the various stakeholders have about ESIS. Thus, Hypothesis 1 includes:

- Hypothesis 1. Stakeholders of sports organizations (SO) are aware of environmental sustainability initiatives in sports (ESIS).

- Hypothesis 1a. Sponsors are aware of ESIS.

- Hypothesis 1b. Employees are aware of ESIS.

- Hypothesis 1c. Members are aware of ESIS.

According to the perspective of Lindsey (2008) [26], individual sustainability is focused on the "maintenance of health outcome for the individual beneficiaries of sustainability initiatives of any programme" (p. 281) and it corresponds in this study to the individual form and to the health and well-being topic. These outcomes may vary according to different 
sports development programmes. In this study, we intend to measure its importance to the different groups of stakeholders. For that, hypothesis 2 was stated, according to the different groups of SO stakeholders:

- Hypothesis 2. Stakeholders of SO classify the health and well-being ESIS topic as the most important.

- Hypothesis 2a. Sponsors of SO classify the health and well-being ESIS topic as the most important.

- Hypothesis 2b. Employees of SO classify the health and well-being ESIS topic as the most important.

- Hypothesis 2c. Members of SO classify the health and well-being ESIS topic as the most important.

Bearing in mind the sustainability forms described in literature [26] and the credibility of sports organizations considering the power to influence the behaviour of sport stakeholders $[2,15,30]$, the third hypothesis was designed, stating the performance of ESIS is considered positive by the different groups of stakeholders. So, in Hypothesis 3 we want to know:

- Hypothesis 3. Stakeholders rate the performance of ESIS as positive.

- Hypothesis 3a. Sponsors rate the performance of ESIS mostly as good or very good.

- Hypothesis 3b. Employees rank the performance of ESIS mostly as good or very good.

- Hypothesis 3c. Members rate the performance of ESIS mostly as good or very good.

Study 2

Study 2 concentrates on one specific research Hypothesis 4, multiplied according to the different groups of stakeholders: sponsors (Hypothesis 4a), employees (Hypothesis 4b), and members (Hypothesis 4c).

It is essential to thoroughly measure the feedback of interested parties (e.g., members, employees, and sponsors) concerning ESIS initiatives [32]. As stakeholders, sponsors see sports organizations as a platform that influences environmental sustainability efforts, thus leveraging the brand [30]. Establishing relationships is a major factor concerning the execution of environmental sustainability initiatives [29] and ESIS can increase fan identification [31]. Following the aforementioned line of reasoning [26], the individual sustainability (longer-term changes in individuals' attitudes, aptitudes and/or behaviour through awareness and/or involvement with the ESIS), the community sustainability (maintenance of changes in the community in which the ESIS is delivered), and the organisational sustainability (the maintenance or expansion of ESIS by the organization responsible for their delivery) will be considered. Thus, the following hypotheses are elaborated:

- Hypothesis 4. There are differences in the sustainability forms between stakeholders, according to their behaviours.

- Hypothesis 4a. It is expected that sponsors give more value to the sustainability organizational form of ESIS.

- Hypothesis $4 \mathrm{~b}$. It is expected that employees give more value to the sustainability community form of ESIS.

- Hypothesis 4c. It is expected that members give more value to the sustainability individual form of ESIS.

The basis for the design of the conceptual research model depicted in Figure 2 considered the large dimension of the sample $(n=5917)$. 


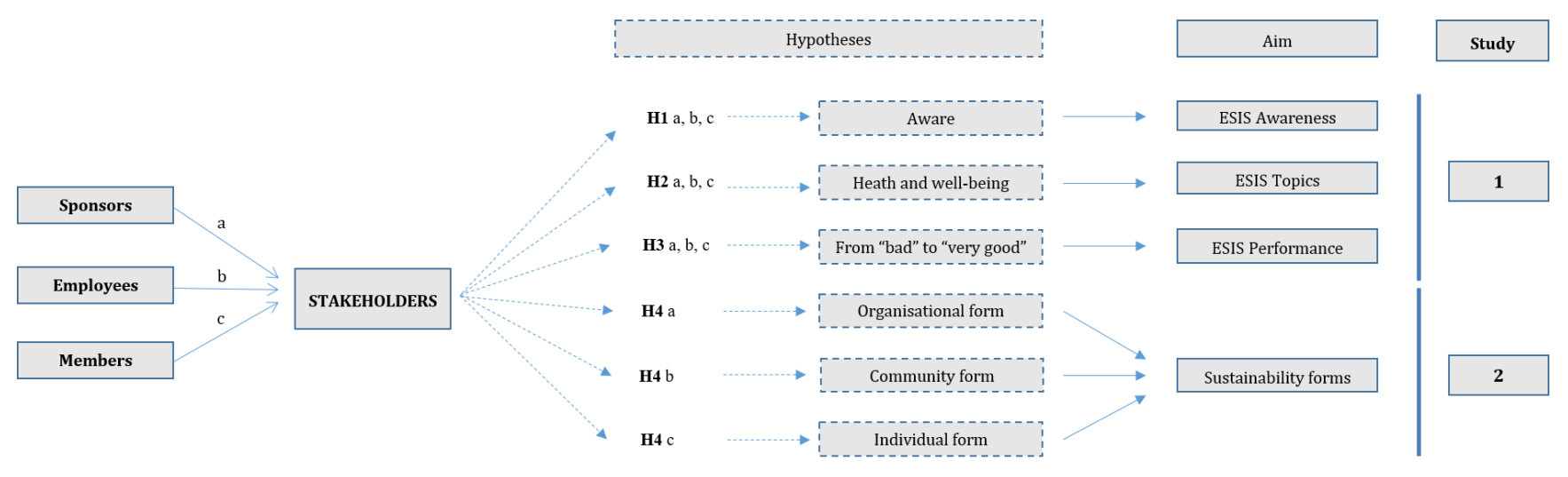

Figure 2. Conceptual research model for study 1 and study 2.

\section{Materials and Methods}

This study was conducted with members, employees, and sponsors of Futebol Clube do Porto (FCP), a team competing in the Portuguese top football league (Liga Portugal), acknowledged as the 6th strongest football league worldwide [69]. FCP is among the teams with the largest base of followers [70]. The quantitative research was based on an empirical study consisting of the dissemination by e-mail of an online survey among the FCP stakeholders. The survey was available online during five consecutive weekdays in June of 2020, and a total of 5917 responses were collected. To analyse the collected data, a descriptive statistical analysis using SPSS 25.0 was developed. The analysis procedure in this study conducted a frequency analysis to identify the representativeness of each group of respondents in the total amount of the sample, according to the research goals. Regarding the excluding variable, only 2090 of the responses were considered for hypothesis testing.

\section{Results and Discussion}

The findings from the empirical data are discussed in relation to literature from the two studies developed, focusing on the identification of the stakeholders who are aware of ESIS, regarding their classification on the most important topic of ESIS and their categorization on the organization's ESIS performance (Study 1), and determining the differences among the groups of stakeholders in the topics covered (Study 2).

\subsection{Study 1}

The objective of study 1 is triple:

- what is the percentage of those who are aware of the environmental sustainability initiatives carried out (global and by group);

- of the topics considered most relevant in terms of FC Porto's action, what is the ranking in terms of their importance;

- by group, what is the global classification regarding the performance of the sports organization in the area of environmental sustainability.

Study 1 contains a question with an exclusion character, and two questions whose answers give rise to a classification by topic and by group. With the question "Are you aware of the initiatives developed by FC Porto in the area of environmental sustainability?", we can exclude those who are not familiar with the environmental sustainability initiatives. Regarding the total sample, it was possible to verify that the vast majority of the respondents $(64.7 \%$, $\mathrm{n}=3827$ ) were not aware of the environmental sustainability initiatives (ESIS) promoted by the organization. Considering the ones who admit knowing about the existence of these initiatives, in a group analysis $(35.3 \%, \mathrm{n}=2090)$, about half $(52.9 \%)$ of the employee respondents were aware, which contrasts with the fact that about a third of the members $(34.9 \%)$ and only about a quarter of sponsors $(25.5 \%)$ were aware of the initiatives carried out (Table 1). 
Table 1. Stakeholders ESIS awareness.

\begin{tabular}{cccc}
\hline Groups & Classifications & Frequency (n) & Percentage (\%) \\
\hline \multirow{3}{*}{ Sponsors } & Awareness & 13 & 25.5 \\
& Not awareness & 38 & 74.5 \\
& Total & 51 & 100 \\
\hline \multirow{3}{*}{ Employees } & Awareness & 91 & 52.9 \\
& Not awareness & 81 & 47.1 \\
& Total & 172 & 100 \\
\hline \multirow{2}{*}{ Members } & Awareness & 1986 & 34.9 \\
& Not awareness & 3708 & 65.1 \\
& Total & 5694 & 100 \\
\hline
\end{tabular}

To test H1, checking if there are differences between the ESIS awareness level between the different groups of stakeholders (SEM-sponsors, employees, members), the chi-square test was used. It was found that there is a significant association between SEM and ESIS awareness, noting that this is significantly higher in the group of employees compared to the other two groups of stakeholders $(p<0.001)$.

As for the relevant topics of action for FC Porto in the scope of sustainability ((a) climate changes and energy consumption-CC; (b) environmental impact of sporting eventsEI; and (c) promotion of health and well-being-HW), a Likert scale of five points was provided for the respondents to classify the level of importance given to each one of them. With regard to the sustainability topics covered, the "Health and Well-being" was the most valued by all stakeholders, synonymous with a maximized individual perspective of a global phenomenon such as sustainability. The results in Table 2 show that the health and well-being dimension is the most valorised sustainable form among the total of the sample (n = 2090) (Table 2).

Table 2. SEM classification by topic.

\begin{tabular}{cc}
\hline Sustainability Topics & Average \\
\hline Climate changes (CC) & 3.98 \\
Environmental impact (EI) & 3.94 \\
Health and well-being (HW) & 4.13 \\
\hline
\end{tabular}

To test H2, the Friedman test was calculated, revealing there is statistical significance in the assessments made by the stakeholders to the different levels of ESIS $(p<0.001)$. Regarding pairwise comparisons between ESIS levels (among SEM), it is possible to confirm $\mathrm{H} 2$, considering the existence of statistically significant differences in the HW dimension, compared to the CC $(p<0.001)$ and to the EI dimension $(p<0.001)$. However, considering $\mathrm{H} 2 \mathrm{a}, \mathrm{H} 2 \mathrm{~b}$ and $\mathrm{H} 2 \mathrm{c}$, it was possible to verify through the Friedman test that this trend was confirmed only in the case of members $(p<0.001)$.

Finally, for the question "How do you evaluate the performance of FC Porto in the area of environmental sustainability?", the respondents who know about its existence $(\mathrm{n}=2090)$ could classify the performance in five categories: very good, good, medium, bad, very bad. Regarding a group analysis, we followed the classification trend of "very good" and "good", and added the respective classification percentages. The group of "employees" and "members" reached very high similar numbers ( $92.3 \%$ and $91.5 \%$, respectively). The sponsors group stood at $84.5 \%$ (Table 3 ).

To test H3, the Kruskal-Wallis test was applied, confirming there are no significant differences between the stakeholders' groups $(p>0.05)$ regarding ESIS performance.

\section{Conclusion}

Sports organizations are credible in communicating messages related to the promotion of environmentally sustainable behaviors to the various stakeholders (see Table 3), but the 
level of knowledge of the messages must be improved for all stakeholders, particularly the sponsors (see Table 1). Overall, the environmental sustainability initiative on the topic of health and well-being is valued as the most relevant (see Table 2).

Table 3. Global performance classification by group.

\begin{tabular}{cccc}
\hline Groups & Classifications & Frequency (n) & Percentage (\%) \\
\hline \multirow{3}{*}{ Sponsors } & Very good & 3 & 23.1 \\
& Good & 8 & 61.5 \\
& Medium & 2 & 15.4 \\
\cline { 2 - 4 } Employees & Total & 13 & 100 \\
& Very good & 34 & 37.4 \\
& Good & 50 & 54.9 \\
& Medium & 7 & 7.7 \\
\hline \multirow{3}{*}{ Members } & Total & 91 & 100 \\
& Very good & 754 & 37.9 \\
& Good & 1064 & 53.6 \\
& Medium & 156 & 7.9 \\
& Bad & 10 & 0.5 \\
& Very bad & 2 & 0.1 \\
\hline
\end{tabular}

\subsection{Study 2}

The purpose of study 2 was to identify the differences of sustainability forms among groups of stakeholders (sponsors, employees, and members), regarding the topics of ESIS organizations.

Sponsors. We first analyze the group of sponsors. Regarding a group analysis, the topics that attained a higher mean in the case of sponsors were CC and EI with 4.15 (Table 4). In the light of these results, ESIS related with organizational and community forms were the ones more valorized by this group of stakeholders.

Table 4. ESIS performance by group (sponsors).

\begin{tabular}{ccccccccc}
\hline \multicolumn{10}{c}{ Sponsors } \\
\hline $\mathbf{C C}$ & $\mathbf{n}$ & $\mathbf{\%}$ & $\mathbf{E I}$ & $\mathbf{n}$ & $\mathbf{\%}$ & $\mathbf{H W}$ & $\mathbf{n}$ & $\mathbf{\%}$ \\
\hline 1 & 1 & 7.7 & 1 & 0 & 0 & 1 & 1 & 7.7 \\
2 & 0 & 0 & 2 & 1 & 7.7 & 2 & 0 & 0 \\
3 & 2 & 15.4 & 3 & 1 & 7.7 & 3 & 4 & 30.8 \\
4 & 3 & $\mathbf{2 3 . 1}$ & 4 & 6 & $\mathbf{4 6 . 2}$ & 4 & 1 & 7.7 \\
5 & 7 & $\mathbf{5 3 . 8}$ & 5 & 5 & $\mathbf{3 8 . 5}$ & 5 & 7 & 53.8 \\
\hline 4.15 & & & 4.15 & & & 4.00 & & \\
\hline
\end{tabular}

Employees. Afterwards, we analyze the employees' group, the ones that have a greater daily experience of the club from a physical and professional perspective. Among the employees, with a mean of 4.13, the individual sustainability form of HW was the most valorized (Table 5).

Members. Finally, the group with the elements characterized as the ones with a high psychological and emotional connection to the club, the members group, was analysed. Regarding what the importance given to the different topics of sustainability initiatives, members expressed the same trend as the employees group (i.e., mean of 4.13), valorizing the most the individual dimension of HW (Table 6).

To test Hypothesis 4, Kruskal-Wallis was calculated, confirming there is no significant statistical difference between SEM, regarding the importance given to the three ESIS levels $(p>0.05)$ (Table 7). 
Table 5. ESIS performance by group (employees).

\begin{tabular}{ccccccccc}
\hline \multicolumn{10}{c}{ Employees } \\
\hline CC & $\mathbf{n}$ & $\mathbf{\%}$ & EI & $\mathbf{n}$ & $\mathbf{\%}$ & $\mathbf{H W}$ & $\mathbf{n}$ & $\mathbf{\%}$ \\
\hline 1 & 5 & 5.5 & 1 & 5 & 5.5 & 1 & 6 & 6.6 \\
2 & 5 & 5.5 & 2 & 5 & 5.5 & 2 & 6 & 6.6 \\
3 & 8 & 8.8 & 3 & 7 & 7.7 & 3 & 5 & 5.5 \\
4 & 30 & 33 & 4 & 35 & 38.5 & 4 & 27 & 29.7 \\
5 & 43 & 47.3 & 5 & 39 & 42.9 & 5 & 47 & 51.6 \\
\hline 4.11 & & & 4.08 & & & 4.13 & & \\
\hline
\end{tabular}

Table 6. ESIS performance by group (members).

\begin{tabular}{ccccccccc}
\hline & \multicolumn{8}{c}{ Members } \\
\hline $\mathbf{C C}$ & $\mathbf{n}$ & $\mathbf{\%}$ & $\mathbf{E I}$ & $\mathbf{n}$ & $\mathbf{\%}$ & $\mathbf{H W}$ & $\mathbf{n}$ & $\mathbf{\%}$ \\
\hline 1 & 147 & 7.4 & 1 & 132 & 6.6 & 1 & 134 & 6.7 \\
2 & 82 & 4.1 & 2 & 111 & 5.6 & 2 & 60 & 3 \\
3 & 297 & 15 & 3 & 314 & 15.8 & 3 & 216 & 10.9 \\
4 & 614 & $\mathbf{3 0 . 9}$ & 4 & 636 & $\mathbf{3 2}$ & 4 & 586 & $\mathbf{2 9 . 5}$ \\
5 & 846 & $\mathbf{4 2 . 6}$ & 5 & 793 & $\mathbf{3 9 . 9}$ & 5 & 990 & $\mathbf{4 9 . 8}$ \\
\hline 3.95 & & & 3.93 & & & 4.13 & & \\
\hline
\end{tabular}

Table 7. ESIS importance to SEM, by level.

\begin{tabular}{cc}
\hline Sustainability Dimensions & Sig. \\
\hline Climate changes (CC) & 0.402 \\
Environmental impact (EI) & 0.449 \\
Health and well-being (HW) & 0.922 \\
\hline
\end{tabular}

\section{Conclusion}

Sponsors give more value to the sustainable organizational and community form of ESIS. Sponsorship is understood as a way to increase brand awareness. The fact that the sports organization carries out environmental sustainability initiatives provides leverage to the associated brand and may even reach less knowledgeable audiences. Following the results, employees and members give more value to the individual form of ESIS, characterized by an individual form. An intense identification with the sports organization, combined with the creation of a strong relationship, leads to the development of a high individualization on the part of those who spend more hours in the club (i.e., employees) and/or more emotionally connected to the club (i.e., members).

\section{General Discussion}

The vast majority of the respondents $(64.7 \%, \mathrm{n}=3827)$ are not aware of the environmental sustainability initiatives (ESIS) promoted by the organization, confirming the conclusions of other studies [6]. Of those who were aware, the largest percentage goes to "employees", barely surpassing 50\%. In sponsors, the overwhelming majority (74.5\%) were not aware of the ESIS, which is indicative of the little importance (or attention) that this stakeholder employs to issues related to environmental sustainability. Members are the "great support" of sports organizations and, in the analysis of the results obtained in terms of awareness of the initiatives (34.9\%), there is much to be done to increase the level of identification with the club, through better communication of the ESIS.

In the overall sample, stakeholders who were aware of the sports organization's sustainability initiatives mainly value the ESIS from a health and well-being point of view. Of the topics analysed under the environmental sustainability theme "climate changes 
and energy consumption", "environmental impact of sport events", and "health and wellbeing", the most valued form of sustainability was the individual, which refers to a more personal perspective in the interpretation of the sustainability topics in question [59].

Sport organizations are seen as credible in passing messages through ESIS. In fact, the data collected confirms previous studies [2,15,30,37]. As for performance in the area of environmental sustainability, we added the two highest ratings for each stakeholder group ("good" and "very good"). The results are very positive, obtaining a minimum value of $84.5 \%$ for sponsors and a maximum value of $92.3 \%$ attributed by employees. Noteworthy is the low degree of response percentage from sponsors (25\%) who were aware of the ESIS performed. From a commercial and business perspective, having feedback on the money that is spent and the actions that are carried out is a sign of good practice.

There are no significant differences between the three groups under analysis. However, there is a tendency for sponsors to attach greater importance to organizational and community initiatives as sustainability forms, as the topics "climate changes and energy consumption" and "environmental impact of sports events" indicate. In this way, we have greater understanding by knowing the sponsors' opinions about sustainability actions, extending the work previously carried out [12,30]. The opposite trend is observed in employees and members, with an individual predominance characterized by a long-term change in attitudes and behaviors, observed in the topic "health and well-being". Interestingly, the community form is the least significant in these two groups, which is relevant as a result. These two groups are concerned with the extremes ("health and well-being" from an individual form and "climate changes and energy consumption" from an organizational form), with the community form of sustainability, which is more specific and contextualized, in last place.

\section{Conclusions}

This study focuses on ESIS and stakeholder analysis, regarding topics considered relevant to sports organization with defined objectives and measurement metrics [32]. In this study we were able to identify the percentage of stakeholders who were aware of the ESIS carried out by the club, the importance of the health and well-being focus in the ESIS, as well as the credibility of sports institutions in passing on messages related to environmentally sustainable behavior. Different stakeholder groups have different strategies depending on how ESIS topics are approached. The results of this study allow for a better understanding of the behavior of stakeholders and their positions according to sustainability forms, allowing the development of strategies and campaigns specifically aimed at different stakeholders. Managerial implications of the study may help the sports organizations to improve ESIS communication while raising awareness and participation, but, above all, having strategies, clear objectives, measures of success, or specific summaries of what was intended to be achieved [5-7].

Regarding study limitations, we may refer the fact that it is focused on only one case. However, presenting avenues for future research, the research may be extended to other sports organizations in Portugal and in other European countries, and professional sports organisations from other kinds of sports, and also national and international athletic federations and leagues, with the goal of developing a comparative analysis that may bring more complete results regarding the subjects in analysis.

Author Contributions: Conceptualization, R.R.C.; methodology, R.R.C. and J.A.Q.; formal analysis, R.R.C. and J.A.Q.; investigation, R.R.C., J.A.Q. and T.S.; resources, T.S.; data curation, J.A.Q.; writing-original draft preparation, R.R.C. and J.A.Q.; writing-review and editing, R.R.C. and J.A.Q.; supervision, R.R.C., T.S. and J.A.Q. All authors have read and agreed to the published version of the manuscript.

Funding: This research received no external funding.

Institutional Review Board Statement: Not applicable.

Informed Consent Statement: Not applicable. 
Data Availability Statement: Data is contained within the article.

Conflicts of Interest: The authors declare no conflict of interest.

\section{References}

1. United Nations. Report of the World Commission on Environment and Development Our Common Future-Report of the World Commission on Environment and Development; Report No: A/42/427; UN: Oslo, Norway, 1987; p. 247. Available online: File:///C: /Users/Utilizador/Downloads/our_common_futurebrundtlandreport1987.pdf (accessed on 8 April 2021).

2. Casper, J.M.; Pfahl, M.E.; McCullough, B.P. Is Going Green Worth It? Assessing Fan Engagement and Perceptions of Athletic Department Environmental Efforts. J. Appl. Sport Manag. 2017, 9, 106-134. [CrossRef]

3. Inoue, Y.; Kent, A. Investigating the role of corporate credibility in corporate social marketing: A case study of environmental initiatives by professional sport organizations. Sport Manag. Rev. 2012, 15, 330-344. [CrossRef]

4. Inoue, Y.; Kent, A. Sport Teams as Promoters of Pro-Environmental Behavior: An Empirical Study. J. Sport Manag. 2012, 26, 417-432. [CrossRef]

5. Mccullough, B.P.; Orr, M.; Kellison, T.B. Sport Ecology: Conceptualizing an Emerging Subdiscipline Within Sport Management. J. Sport Manag. 2020, 34, 509-520. [CrossRef]

6. Trail, G.T.; McCullough, B.P. Marketing sustainability through sport: Testing the sport sustainability campaign evaluation model. Eur Sport Manag. Q. 2019, 20, 109-129. [CrossRef]

7. Trendafilova, S.; McCullough, B.P. Environmental sustainability scholarship and the efforts of the sport sector: A rapid review of literature. Cogent. Soc. Sci. 2018, 4, 1-15. [CrossRef]

8. Nicolau, J.L. The decision to raise firm value through a sports-business exchange: How much are Real Madrid's goals worth to its president's company's goals? Eur. J. Oper. Res. 2011, 215, 281-288. [CrossRef]

9. Kellison, T.B.; Cianfrone, B.A. Superordinate social identity in a professional sport organization's environmental program. Int. J. Sport Manag. 2020, 21, 1-28.

10. Smith, A.C.T.; Stewart, B. The special features of sport: A critical revisit. Sport Manag. Rev. 2010, 13, 1-13. [CrossRef]

11. Blankenbuehler, M.; Kunz, M.B. Professional Sports Compete to Go Green. Am. J. Manag. 2014, 14, 75-81.

12. Trendafilova, S.; Babiak, K. Understanding strategic corporate environmental responsibility in professional sport. Int. J. Sport Manag. Mark. 2013, 13, 1-26. [CrossRef]

13. Kellison, T.B.; Trendafilova, S.; McCullough, B.P. Considering the social impact of sustainable stadium design. Int. J. Event Manag. Res. 2015, 10, 63-83.

14. Kellison, T.B.; Mondello, M.J. Organisational perception management in sport: The use of corporate pro-environmental behaviour for desired facility referenda outcomes. Sport Manag. Rev. 2012, 15, 500-512. [CrossRef]

15. Casper, J.M.; Pfahl, M.E.; McCullough, B.P. Intercollegiate sport and the environment: Examining fan engagement based on athletics department sustainability efforts. J. Issues Intercoll. Athl. 2014, 7, 65-91.

16. Choi, J.S.A. Going green in baseball-A case study of the SK Wyverns. Int. J. Sport Mark. Spons. 2016, 17, 368-379. [CrossRef]

17. Wall-Tweedie, J.; Nguyen, S.N. Is the Grass Greener on the Other Side? A Review of the Asia-Pacific Sport Industry's Environmental Sustainability Practices. J. Bus. Ethics 2018, 152, 741-761. [CrossRef]

18. Death, C. “Greening” the 2010 FIFA world cup: Environmental sustainability and the mega-event in South Africa. J. Environ. Plan. 2011, 13, 99-117. [CrossRef]

19. Fleischer, M.; Fuhrmann, M.; Haferburg, C.; Krüger, F. "Festivalisation" of urban governance in South African cities: Framing the urban social sustainability of mega-event driven development from below. Sustainability 2013, 5, 5225-5248. [CrossRef]

20. Kellison, T.B.; McCullough, B.P. A forecast for the mainstreaming of environmental sustainability. Sport Entertain. Rev. 2016, 2, 11-18.

21. Duro, A.; Piccione, V.; Ragusa, M.A.; Veneziano, V. New enviromentally sensitive patch index-ESPI-for MEDALUS protocol. AIP Conf. Proc. 2014, 1637, 305-312.

22. Mercado, H.U.; Grady, J. Teaching environmental sustainability across the sport management curriculum. Sport Manag. Educ. J. 2017, 11, 120-127. [CrossRef]

23. McCullough, B.P.; Pfahl, M.E.; Nguyen, S.N. The green waves of environmental sustainability in sport. Sport Soc. 2016, 19, 1040-1065. [CrossRef]

24. Mallen, C.; Stevens, J.; Adams, L.J. A Content Analysis of Environmental Sustainability Research In a Sport-Related Journal Sample. J. Sport Manag. 2011, 25, 240-256. [CrossRef]

25. Trendafilova, S.; Babiak, K.; Heinze, K. Corporate social responsibility and environmental sustainability: Why professional sport is greening the playing field. Sport Manag. Rev. 2013, 16, 298-313. [CrossRef]

26. Lindsey, I. Conceptualising sustainability in sports development. Leis. Stud. 2008, 27, 279-294. [CrossRef]

27. Francis, T.; Norris, J.; Brinkmann, R. Sustainability initiatives in professional soccer. Soccer Soc. 2016, 18, 396-406. [CrossRef]

28. McCullough, B.P.; Cunningham, G.B. A Conceptual Model to Understand the Impetus to Engage in and the Expected Organizational Outcomes of Green Initiatives. Quest 2010, 62, 348-363. [CrossRef]

29. Babiak, K.; Trendafilova, S. CSR and Environmental Responsibility: Motives and Pressures to Adopt Green Management Practices. Corp. Soc. Responsib. Environ. Manag. 2011, 18, 11-24. [CrossRef] 
30. Casper, J.M.; McCullough, B.P.; Pfahl, M.E. Examining environmental fan engagement initiatives through values and norms with intercollegiate sport fans. Sport Manag. Rev. 2020, 23, 348-360. [CrossRef]

31. McCullough, B.P.; Cunningham, G.B. Recycling intentions among youth baseball spectators. Int. J. Sport Manag. Mark. 2011, 10, 104-120. [CrossRef]

32. McCullough, B.P.; Pelcher, J.; Trendafilova, S. An Exploratory Analysis of the Environmental Sustainability Performance Signaling Communications among North American Sport Organizations. Sustainability 2020, 12, 1950. [CrossRef]

33. Sanderson, A.R.; Shaikh, S.L. Economics, sports, and the environment. In Routledge Handbook of Sport and the Environment; McCullough, B.P., Kellison, T.B., Eds.; Routledge: New York, NY, USA, 2017; pp. 36-53.

34. Dobson, S.; Goddard, J. The Economics of Football, 2nd ed.; Cambridge University Press: Cambridge, UK, 2004.

35. Watanabe, N.M.; Yan, G.; Soebbing, B.P.; Fu, W. Air Pollution and Attendance in the Chinese Super League: Environmental Economics and the Demand for Sport. J. Sport Manag. 2019, 33, 289-302. [CrossRef]

36. Orr, M.; Schneider, I. Substitution interests among active-sport tourists: The case of a cross-country ski event. J. Sport Tour. 2018, 22, 315-332. [CrossRef]

37. Mallen, C.; Adams, L.; Stevens, J.; Thompson, L. Environmental sustainability in sport facility management: A Delphi study. Eur. Sport Manag. Q 2010, 10, 367-389. [CrossRef]

38. Dolf, M.; Teehan, P. Reducing the carbon footprint of spectator and team travel at the University of British Columbia's varsity sports events. Sport Manag. Rev. 2015, 18, 244-255. [CrossRef]

39. Triantafyllidis, S. Carbon Dioxide Emissions Research and Sustainable Transportation in the Sports Industry. J. Carbon Res. 2018, 4, 1-5. [CrossRef]

40. Dosumu, A.; Colbeck, I.; Bragg, R. Greenhouse gas emissions as a result of spectators travelling to football in England. Sci. Rep. 2017, 7, 1-7. [CrossRef] [PubMed]

41. Thibault, L. Globalization of Sport: An Inconvenient Truth. J. Sport Manag. 2009, 23, 1-20. [CrossRef]

42. Collins, A.; Roberts, A. Assessing the environmental impact of economic activity surrounding major sports events. In Routledge Handbook of Sport and the Environment; McCullough, B.P., Kellison, T.B., Eds.; Routledge: New York, NY, USA, 2018; pp. 207-219.

43. Locke, S.L. Estimating the impact of Major League Baseball games on local air pollution. Contemp. Econ. Policy 2019, 37, 236-244. [CrossRef]

44. Triantafyllidis, S.; Ries, R.J.; Kaplanidou, K. (Kiki). Carbon Dioxide Emissions of spectators' transportation in collegiate sporting events: Comparing on-campus and off-campus stadium locations. Sustainability 2018, 10, 241. [CrossRef]

45. Wicker, P. The carbon footprint of active sport participants. Sport Manag. Rev. 2019, 22, 513-526. [CrossRef]

46. Cantelon, H.; Letters, M. The making of the IOC environmental policy as the third dimension of the Olympic Movement. Int. Rev. Sociol. Sport 2000, 35, 294-308. [CrossRef]

47. Kellison, T.B.; Casper, J.M. Environmental legacy of mega sport events. In Legacies and Mega Events: Fact or Fairy Tales; Brittain, I., Bocarro, J., Byers, T., Swart, K., Eds.; Routledge: London, UK, 2017; pp. 445-455.

48. Kellison, T.B. Building sport's green houses: Issues in sustainable facility management. In Sport Management and the Natural Environment: Theory and Practice; Casper, J., Pfahl, M.E., Eds.; Routledge: New York, NY, USA, 2015; pp. $218-237$.

49. Trendafilova, S.; Kellison, T.B.; Spearman, L. Environmental sustainability in sport facilities in East Tennessee. J. Facil. Plan. Des. Manag. 2014, 2, 1-10.

50. Casper, J.M.; Pfahl, M.E. Environmental sustainability practices in U.S. NCAA Division III athletics departments. Int. J. Event Manag. Res. 2015, 10, 12-36.

51. Kellison, T.B.; Kim, Y.K. Marketing pro-environmental venues in professional sport: Planting seeds of change among existing and prospective consumers. J. Sport Manag. 2014, 28, 34-48. [CrossRef]

52. Trail, G.T.; Mccullough, B.P. Marketing Sustainability through Sport: The Importance of Target Market Insights. In Routledge Handbook of Sport and the Environment; McCullough, B.P., Kellison, T.B., Eds.; Routledge: London, UK, 2018 ; pp. 134-148.

53. United Nations. The Impact of COVID-19 on Sport, physical Activity and Well-Being and Its Effects on Social Development. Policy Brief No. 73. 2020. p. 4. Available online: https://www.un.org/development/desa/dspd/wp-content/uploads/sites/22 /2020/05/PB_73.pdf (accessed on 5 April 2021).

54. Stará, J. Health and Wellness-Conceptual Grounding. Act. Sal. Vit. 2017, 5, 3-25.

55. Bushell, R. Quality of Life, Tourism and Wellness. In Wellness and Tourism-Mind, Body, Spirit, Place; Bushell, R., Sheldon, P.J., Eds.; Cognizant Communication Corporation: New York, NY, USA, 2009; pp. 19-36.

56. Kickbusch, I. Approaches to an ecological base for public health. Health Promot. Int. 1989, 4, 265-268. [CrossRef]

57. Kelly, C.; Smith, M. Holistic Tourism: Integrating Body, Mind, Spirit. In Wellness and Tourism-Mind, Body, Spirit, Place; Bushell, R., Sheldon, P.J., Eds.; Cognizant Communication Corporation: New York, NY, USA, 2009; pp. 69-83.

58. WHO. Constitution of the World Health Organization. 1948. p. 224. Available online: https://apps.who.int/gb/bd/pdf_files/ BD_49th-en.pdf (accessed on 2 April 2021).

59. Leandro, M.E.; Nogueira, F.; Carvalho, A.B.S. Diversity and Interconnection: Spas, Health and Wellness Tourism. In Health and Wellness Tourism—Emergence of a New Market Segment; Peris-Ortiz, M., Álvarez-Garcia, J., Eds.; Springer: New York, NY, USA, 2015; pp. 153-164.

60. Inoue, Y.; Sato, M.; Filo, K.; Du, J.; Funk, D.C. Sport spectatorship and life satisfaction: A multicountry investigation. J. Sport Manag. 2017, 31, 419-432. [CrossRef] 
61. Inoue, Y.; Sato, M.; Filo, K. Transformative sport service research: Linking sport services with well-being. J. Sport Manag. 2020, 34 , 285-290. [CrossRef]

62. Masdeu Yelamos, G.; Carty, C.; Clardy, A. Sport: A driver of sustainable development, promoter of human rights, and vehicle for health and well-being for all. Sport Bus. Manag. Int. J. 2019, 9, 315-327. [CrossRef]

63. United Nations. Transforming our world: The 2030 Agenda for Sustainable Development. A/RES/70/1. 2015. p. 41 Available online: https://sustainabledevelopment.un.org/content/documents / 21252030\%20Agenda\%20for\%20Sustainable\% 20Development\%20web.pdf (accessed on 5 April 2021).

64. Halden, A. Responding to the Coronavirus crisis. Parallels for tourism and climate change. In Tourism Facing a Pandemic: From Crisis to Recovery; Burini, F., Ed.; Università degli Studi di Bergamo: Bergamo, Italy, 2020; pp. 57-62.

65. Vegara-Ferri, J.M.; Carboneros, M.; Deliautaite, K.; Díazsuárez, A.; López-Gullón, J.M. Fan's perspective about sports events \& COVID-19 confinement period. J. Hum. Sport Exerc. 2020, 16. [CrossRef]

66. Kim, Y.J.; Cho, H.H.; Park, Y.J. 'Leisure Sports Participants' Engagement in Preventive Health Behaviors and Their Experience of Constraints on Performing Leisure Activities During the COVID-19 Pandemic. Front. Psychol. 2020, 11, 3392. [CrossRef] [PubMed]

67. Palathingal, A. The Contribution of Sport to the Achievement of the Sustainable Development Goals: A Toolkit for Action. 2018. p. 58. Available online: https://www.sdgfund.org/sites/default/files/report-sdg_fund_sports_and_sdgs_web.pdf (accessed on 4 May 2021).

68. Ratten, V. Coronavirus disease (COVID-19) and sport entrepreneurship. Int. J. Entrep. Behav. Res. 2020, 26, 1379-1388. [CrossRef]

69. IFFHS, I.F. The Strongest National League in the World 2019-The English Premier League Number 1. 2020. Available online: https:/ / www.iffhs.com/posts/911 (accessed on 21 January 2021).

70. Liga Portuguesa de Futebol Profissional. Liga Portuguesa de Futebol Profissional. Estatísticas. 2015. Available online: https: //www.ligaportugal.pt/pt/liga/estatisticas/espectadores/clube/20162017 (accessed on 21 January 2021). 